\title{
LA DESMATERIALIZACIÓN DE LA HISTORIA EN LA ERA DEL ARCHIVO (CINEMATOGRÁFICO) DE ABY WARBURG A JEAN-LUC GODARD
}

\author{
Natalia Taccetta*
}

\begin{abstract}
Resumo: Aby Warburg proponía en Mnemosyne una escritura de la historia del arte que escapaba a las crono-normatividades de la historiografia que se cristalizaba delante de sus ojos. En su atlas, procuraba un punto de vista anacrónico donde pasado y presente se transforman mutuamente para configurar lo que con Walter Benjamin podría denominarse constelación. Tanto la experiencia warburgiana como algunos archivos cinematográficos de Jean-Luc Godard plantean problemas epistemológicos de gran actualidad: ¿cómo se configura un archivo sobre el pasado y cómo se restituye a los documentos (visuales) un lugar en el proceso histórico? Este artículo explora el modo en que el método de Warburg ilumina producciones contemporáneas sobre la relación entre cine e historia y cómo sigue funcionando como matriz para pensar la desmaterialización de la disciplina histórica.
\end{abstract}

Palavras-chave: Aby Warburg. Jean-Luc Godard. Archivo. Desmaterialización de la historia.

En la década de 1920, Aby Warburg proponía en Mnemosyne una escritura de la historia del arte que escapaba a las crono-normatividades de la historiografía que se cristalizaba delante de sus ojos. En su atlas, procuraba un punto de vista anacrónico, es decir, en la no-coincidencia del tiempo, que no pensara la distancia histórica como obstáculo epistemológico. Allí, pasado y presente se transforman, se critican, se explotan mutuamente para configurar lo que con Walter Benjamin podría denominarse constelación, esto es, una configuración dialéctica de tiempos heterogéneos.

El método warburgiano en Mnemosyne consistía en colocar imágenes una cerca de otra para encontrar similitudes y diferencias a fin de que hicieran aparecer diversos significados. El atlas constituye una "historia del arte sin texto" que comprende unas 1000 fotografías ordenadas según cierto sentido de afinidad. Este permite en el atlas ubicar piezas del Renacimiento junto a fotografías de cuerpos femeninos, esculturas $\mathrm{y}$ publicidades. Parece perseguir un objetivo claro: realizar una lectura crítica de un cuerpo de imágenes a partir de una serie de conceptos. Estos son fundamentalmente los de supervivencia (Nachleben), fórmula emotiva (Pathosformel) y espacio de pensamiento (Denkraum), y funcionan como las coordenadas a partir de las cuales se arma esta suerte de archivo visual de la cultura con documentos artísticos y extra-artísticos que explora las metamorfosis de las figuras a lo largo de la historia y las mutaciones que sufren o celebran las significaciones instituidas.

Mnemosyne plantea a la disciplina histórica un problema epistemológico de gran actualidad: la cuestión de cómo se configura un archivo sobre el pasado y cómo se

\footnotetext{
* Doutora em Ciências Sociais pela Universidad de Buenos Aires e doutora em Filosofia pela Universidade de Paris VIII. Professora na Universidad de Buenos Aires. E-mail: ntaccetta@gmail.com.
} 
restituye a los documentos (visuales) un lugar en el proceso histórico. Como se trata de un atlas de imágenes, la cuestión del documento se replica en el ámbito de la compleja visualidad de la imagen y las relaciones y regímenes de visibilidad. En el atlas, la imagen nunca está sola ni resulta ejemplar, sino que es índice de una intensidad visual -relativa o no al arte- que inaugura un problema que tendrá todo el siglo XX: ¿cómo abordar la imagen en tanto lugar propio (legitimado) de la investigación histórica? Su propia configuración insta al espectador a una lectura inquietante y exige al historiador la tolerancia necesaria para asumir que múltiples trayectorias son posibles. Esto produce una confrontación con la disciplina que convirtió al atlas Mnemosyne en su época en una experiencia vanguardista -incluso posmoderna-, que dejaba al descubierto una prerrogativa controversial del historiador: su trabajo creativo. Warburg desmaterializa la historia del arte tradicional para habilitar una nueva comprensión de la historicidad sin soslayar que esta nueva consideración plantea por elevación un interrogante epistemológico clave en el contexto de la historia del arte o, más en general, a la historia de la imagen: ¿cómo conocer?

Como práctica archivística, Mnemosyne implica la desactivación de categorías fundamentales en la historia del arte hegemónica como las de obra o autor; o clasificaciones ligadas a la configuración de la temporalidad como las de tendencia, período o contexto. No es que estas taxonomías dejen de existir o incluso de funcionar, sino que constituyen lugar de trabajo, tránsito y conflicto para el abordaje espaciotemporal de documentos.

El archivo warburgiano se vuelve un campo problemático donde la definición arqueológica de Michel Foucault parece reactualizarse. En Arqueología del saber (1969), se definía el archivo como "la ley de lo que puede ser dicho"; es decir, se proponía un abordaje del relato sobre el pasado en términos de legalidad, esto es, de las reglas de enunciación que habilitan todo posible decir. Se vuelve evidente la impronta en el argumento del Friedrich Nietzsche de la Segunda intempestiva Sobre la utilidad y el perjuicio de la historia para la vida, escrita entre 1873 y 1874. Allí, Nietzsche critica la imagen homogénea y sucesiva del tiempo, a la que considera un modo "pesimista" y hasta "enfermizo" de enfrentar la vida en la medida en que se opone a una apropiación positiva del pasado. Ese pasado homogéneo e inamovible genera una sensación de impotencia y parálisis que para el filósofo decanta, naturalmente, en un resentimiento profundo que impide una apropiación de la historia. Por eso contempla diversas maneras en las que el pasado habita el presente y el presente experimenta el pasado, atravesándose, afectándose, dislocándose y conmoviéndose mutuamente al tiempo que solicitando las seguridades de la contemporaneidad. Esta propuesta obliga a la historia a interpretar los acontecimientos en un ejercicio permanente, en una práctica historiadora consciente del peligro de las meras continuidades y la necesidad de las fugas y los hiatos.

Comprender la dinámica del proceso histórico de acuerdo a estas premisas implica en Warburg constituir un repertorio visual (material) de formas decisivas para la creación artística; un repertorio iconográfico que desmaterializa el canon y los abordajes hegemónicos volviendo a esta nueva historia una colección (inexorablemente inmaterial) de contingencias e interpretaciones. Así, realiza una iconología crítica que separa las superficies no escuchadas que recubrieron los símbolos de la antigüedad para trazar las continuidades inadmisibles en la historiografía tradicional. 
El lector/espectador de Mnemosyne deambula en un archivo iconográfico captando o inaugurando recorridos sobre una red visual de desvíos y gestos que portan las fórmulas emotivas que con obsesión busca Warburg. Es la búsqueda de estos gestos lo que hace que Mnemosyne vaya mucho más allá de la materialidad de la colección en la medida en que define un campo trans-iconográfico, tal como propone Georges Didi-Huberman (2001, p. 145), que instala la pregunta por la relación entre la historia y la imagen. Con esta operación, Warburg realiza una práctica nueva del documento donde a partir del montaje emergen dimensiones de la historia hasta lograr un tramado nunca definitivo, donde la propia actividad histórica despeja progresivamente las líneas teóricas y permite la emergencia de conexiones.

El atlas constituye, entonces, un enorme repositorio de retablos de una memoria activa, convocada por los documentos a través del montaje. Este tiene, precisamente, la función de desmontar las líneas tradicionales y esperables, es decir, deconstruye las categorías para que, sin determinaciones, la imagen siga su propio recorrido históricoafectivo. Este gesto absolutamente radical en la historiografía del arte hace estallar las consideraciones conocidas hasta entonces, pero sigue constituyendo un modelo de intervención relativo al vínculo entre imagen, historia y relatos hegemónicos.

Operaciones warburgianas como las del corte, el reencuadre, la yuxtaposición, el remontaje, entre otras, tienen la particularidad de constituir el cine del que fue contemporáneo y propiciar su capacidad de producir "acercamientos disociativos" (DIDIHUBERMAN, 2002, p. 474). La aparente paradoja de este sintagma se desarma si se logra leer la urgencia analítica (en el sentido fuerte del término) de Warburg. Con el montaje/desmontaje no se busca un original que se disocia o de un inventario de imágenes originales que se repiten, sino que se supera "la disposición canónica del cuadro comparativo, en la medida misma en que una forma no-ortodoxa de dialéctica, una dialéctica proliferante, viene a reemplazar toda veleidad de dialéctica unificante" (DIDIHUBERMAN, 2002, p. 475). Esta no-clausura en un nuevo significado es lo que convierte a Mnemosyne en una experiencia, incluso una no traducible a la oralidad. La dialéctica obliga a permanecer en la inquietud de una no-superación y una no-resolución, haciendo que el significado y sus potencialidades heurísticas migren incansablemente.

La proliferación conduce a una relación no-unívoca entre causa y efecto, uno de los principios fundamentales de la historiografía decimonónica con la que Warburg discute. Propone una particular relación con el espacio (de la imagen, entre imágenes) y con el tiempo (imposible de recomponer en historicidades definitivas). Es en este sentido que Menmosyne inaugura no sólo una forma posible de hacer historia, sino un campo metodológico que implica un cuestionamiento radical a la idea de continuidad. Las descripciones históricas del atlas se agrupan por la actualidad del saber. Actualidad que concibe a la imagen como una red, integrada a una suerte de museo imaginario creado en cada uno de los lectores/espectadores. Se trata de un dispositivo que funda un instante de historicidad que siempre está inaugurándose, siempre diseminándose. Es la imagen la que encuentra su lugar en el conjunto sin que sea ni predecible ni claramente determinable.

El historiador traza recorridos posibles siguiendo derivas afectivas que no tienen más origen que la contingencia del acto de "ir" el pasado. Es en este sentido que Mnemosyne funciona como un terreno de experimentación visual que obliga a establecer 
una relación intempestiva (nunca fijada) con la imagen y sus huellas. Allí la creación funciona como una operación epistemológica, un acto siempre fundador, que configura un atlas de signaturas tal como propone Maud Hagelstein (2009).

En el pensamiento de Giorgio Agamben, "signatura" adquiere un sentido eminentemente metodológico cuando recoge la tradición filosófica de la secularización asumiendo que muchos de sus términos son, en realidad, signaturas y que tienen una función estratégica. Si "la secularización actúa en el sistema conceptual de lo moderno como una signatura que lo reenvía a la teología” (AGAMBEN, 2009, p. 19), entonces, aquello secularizado exhibe como una marca su pertenencia a la esfera teológica en el pasado. Así lo plantea en Signatura rerum, su libro metodológico, donde Agamben indaga sobre la antiquísima teoría de las signaturas que, desde la Edad Media, intenta descubrir las "marcas" que colocan a las cosas en un lugar específico de la Creación. Casi completamente abandonada durante la Ilustración, la teoría es retomada por Giovanni Morelli en el siglo XIX y, durante el siglo XX, vuelve a ser objeto de estudio gracias a Walter Benjamin y Michel Foucault.

La signatura no es algo tan simple como la causa de algo, sino que tiene, a su vez, un efecto sobre el signador. Agamben se detiene especialmente en el análisis de la lengua como paradigma de toda signatura donde la relación signatura/signado no se agota en una relación de semejanza, pues la lengua como Kunst Signata [arte signada] implica que hay que entender la semejanza en un sentido inmaterial. Las signaturas vinculan al signator y a lo signado en una relación de dislocación por medio de la cual este último revela su virtud escondida (por eso la relación significante/significado no es suficiente para definir la signatura, pues hace falta tener en cuenta el signator). Según Agamben, cuando el signator es el hombre (y no Dios) se producen signaturas como el "pequeño trozo de tela amarilla" que los judíos debían llevar sobre la ropa o la signatura que representa el acto de firmar, el sello impreso en una carta, las letras del alfabeto. La estructura de estas signaturas humanas implica que, cuando se reconoce una signatura, se pone en relación el objeto con aquel a quien se le atribuye como creador. En este sentido, Agamben asegura que la relación introducida por la signatura es, en la cultura occidental, tan importante que el reconocimiento de la signatura modifica sustancialmente el modo de observar los objetos.

\footnotetext{
La signatura no expresa simplemente una relación semiótica entre un signans y un signatum; más bien, es aquello que, insistiendo en esta relación pero sin coincidir con ella, la desplaza y disloca en otro ámbito y la inserta en una nueva red de relaciones pragmáticas y hermenéuticas (AGAMBEN, 2009, p. 57).
}

Si las signaturas no sólo remiten a un significado, desplazan la relación a la esfera pragmático-política y es por eso que el "trozo de tela amarillo" no sólo remite a "judío" como un significado, sino que implica un estigma político-religioso. La signatura, entonces, ya no es aquello que indica la remisión a un ámbito determinado ni la virtud oculta en los elementos naturales, sino que es un "operador" que permite inteligir cierto aspecto del mundo. Esta intelección se lleva a cabo en Mnemosyne asumiendo las posibilidades de la proliferación y encontrando el significado en destellos amenazados con desaparecer. 


\section{ATLAS KINOFOTOGRÁFICO Y ANACRÓNICO}

Esta operatividad de la signatura en la lectura agambeniana parece conformarse bien con la tentativa de Warburg de convertir a la imagen en signatura de un fragmento del pasado. Fragmentos que involucran, como propone Didi-Huberman, un inventario de estados psíquicos y corporales en la imagen figurativa europea. Esos destellos de pasado se replican y reflejan en diversas narrativas y se combinan entre sí a partir de la extrañeza cuya capacidad es la de poder intensificar un gesto en el tiempo fantasmal (nodeterminado, incesante, inquietante) de las supervivencias. La extrañeza alude a una colisión anacrónica del ahora y el pasado; una puesta en crisis de la historiografía que no se permite asumir lo originario sólo como supervivencia.

Las pervivencias en la imagen funcionan como espacios que se cargan de afecto. De allí la noción de Toposformel que habilita pensar no solo la relación entre el lugar (el que se ocupa en el atlas, el que aparece representado, el que se sugiere, al que se apela sin designar) y la emoción, sino que también permite pensar el modo en que los espacios están atravesados por el pathos inaugurando el movimiento y dando lugar a un archivo que podría denominarse "kinofotográfico". El archivo warburgiano realiza una operación sobre la materialidad de la imagen para derivar en la inmaterilidad del tiempo y el movimiento en absoluto sin parangón en el cine.

Tiempo, espacio y movimiento parecen principios eminentemente cinematográficos. En este sentido, Mnemosyne funciona como un modelo de espaciotemporalidad adonde van a recalar los movimientos de la historia, los pliegues de la imagen y la imagen en movimiento. Especialistas como Philip-Alain Michaud o Karl Sierek detectaron esta cualidad cinemática en el pensamiento warburgiano e identificaron en el movimiento su rasgo principal. Estas intuiciones "se perciben en las conferencias de Warburg hacia fines de los años 1890, en las que "proyecta un espacio integral de representación y narración cuyas relaciones sujeto/objeto reenvían al espacio imaginario de otro arte, que sería inventado dos años más tarde: el cine" (SIEREK, 2009, p. 99). La obra de arte en el atlas de Warburg captura al sujeto en acción para hacerlo partícipe del movimiento de la historia. En este sentido, Sierek propone que entre presente y pasado, la imagen constituye un puente que contiene una supervivencia cuya función parece ser la de "provocar un efecto de intensificación y dinamización de las imágenes" (2009, p. 18). Aquello que en la imagen resiste la abre al tránsito por la historia volviéndola "comprensible en su historicidad y actualidad como fuerza dinámica" (2009, p. 18). Este vínculo entre historicidad y actualidad parece poner en evidencia la vocación de la imagen por pertenecer al pasado y al presente, recordando la complejidad de pensar lo contemporáneo sin atender a este vínculo problemático, que es distancia, pero una distancia que vuelve inteligible la propia cercanía.

Esta dinámica de lejos/cerca se produce también en el dispositivo de Warburg: allí, "el movimiento resulta de una transformación de la energía estática en la imagen" (SIEREK, 2009, p. 27) que redunda en una dinamización de la mirada de los espectadores $\mathrm{y}$ una puesta en movimiento del pensamiento de las imágenes en la historia y en las historias. 
Warburg quería comprender cómo la energía de una cultura genera sus propios imaginarios afectivos. Entre otras operaciones, obligando a leer la superposición de tiempos que articulan la historia, cristalizados en las imágenes de la historia del arte. Construye un nuevo modelo de temporalidad a partir de las supervivencias, es decir, los tiempos que se contradicen como síntomas y que las imágenes desvelan más allá de los relatos convencionales. Georges Didi-Huberman lo explicita claramente:

\begin{abstract}
El punto de vista anacrónico - más allá del historicismo tradicional- debería tener la potencia para descubrir esta complejidad: comprender la dinámica de supervivencias en juego; describir cómo (...) lo inmemorial de una experiencia responde a una práctica actual para formar un relámpago, una constelación, la 'imagen dialéctica' de un objeto anacrónico o, para decirlo de una forma más nietzscheana, de un objeto inactual (DIDI-HUBERMAN, 2008, p. 14)
\end{abstract}

Siguiendo esta huella warburgiana, Agamben propone una suerte de definición de cultura como aquello que "es esencialmente un proceso de transmisión y de Nachleben" (AGAMBEN, 1995, p. 157), evocando la "supervivencia" o "sobrevida" o, en una traducción más literal, "después-de-vida" (nach: después y Leben: vida). Sin embargo, no designa una vida más allá de esta vida, sino una vida continuada en este mundo con un halo fantasmal, lo que no resulta casual si se tiene en cuenta que Warburg describía sus escritos como "historias de fantasmas para adultos" (DE LA DURANTAYE, 2009, p. 70).

Las dificultades de traducción esconden una concepción donde las imágenes del pasado cultural no están muertas, sino que se encuentran latentes o inactivadas, pero portan las energías que la cultura ha depositado en ellas -un potencial dinámico que retienen aún cuando han sido olvidadas por períodos muy prolongados. En Warburg, Agamben encuentra que "precisamente lo que debería haber aparecido como una estructura inconsciente por excelencia - la imagen- se muestra a sí misma como un elemento histórico decisivo, el verdadero lugar de la actividad cognitiva humana en su confrontación vital con el pasado" (2007, p. 185). En este sentido, es posible asumir que Warburg transformó la imagen en un "elemento decisivamente histórico y dinámico" (AGAMBEN, 2001, p. 52). Posiblemente, una de las mayores aspiraciones warburgianas haya sido comprender y describir las energías inherentes a las imágenes de la cultura, esto es, las energías "guardadas" en esas imágenes que esperan ser revividas en las imaginaciones de otras épocas.

Dejando de lado la ilusión de la sucesión y la eucronía, la matriz conceptual trazada por Warburg hace imposible concebir la temporalidad más que a partir de la interrupción del orden lineal del tiempo homogéneo, ubicando la imagen en un lugar privilegiado a partir de un desocultamiento de la discontinuidad y la contingencia. Presente y pasado (de los acontecimientos, de las obras, de las imágenes) se imbrican mutuamente, pues el pasado no es aquello que, desde el más allá, determina el presente, sino que es un objeto en continua y necesaria construcción. Por eso, recordar no es volver presente lo que fue, sino apropiarse del pasado, citarlo, seleccionarlo, montarlo, reencuadrarlo y evaluarlo. Producto de la anacronía y la contaminación de tiempos superpuestos, las imágenes estéticas dislocan el orden establecido y trastocan la vida. Irrumpen intempestivamente 
con nuevas consideraciones sobre el presente y elementos renovados para inteligir el pasado, evitando presentarse como totalidad. Esta impertinencia de las imágenes pone de manifiesto que la temporalidad no es del orden de la sucesión, sino que surge -como querría Benjamin- de un tipo de montaje. Tal como lo piensa Didi-Huberman, el anacronismo obliga a repensar el modelo del tiempo porque impone una reflexión sobre la teoría de la historia, pero también porque cuestiona la propia verdad de la continuidad histórica. Deviene, entonces, una intención de representación que desplaza la interpretación de su soporte temporal alrededor de un sistema más englobante, la constelación, a fin de devenir una presencia activa, organizadora y "uniformadora".

La imagen sigue siendo independiente de un sujeto susceptible de proyectarla e imaginarla; no se reduce a un producto de la interiorización del historiador. El valor histórico de una imagen del pensamiento tendrá siempre presencia sobre toda otra concepción que el historiador pueda declinar: este tratamiento histórico deviene así revelador de un discurso, de rupturas ideológicas, culturales o de la continuidad simbólica. Esta perspectiva de análisis no consiste solamente en transformar el pasado en imágenes, sino en hacer de toda realidad, pasada o actual, una sucesión que muestre las diversas imágenes del pensamiento.

Didi-Huberman no propone posarse frente a las imágenes con ingenuidad, pero sí con cierta perplejidad y ansias de conocimiento. Estar frente a la imagen es a la vez cuestionar los fundamentos del propio conocimiento:

[...] sin temor ni a no saber más (al momento en que la imagen nos despoja de nuestras certezas) ni a saber más (desde el momento en que hace falta comprender este despojamiento en sí, comprenderlo a la luz de algo mucho más vasto que concierne a la dimensión antropológica, histórica o política de las imágenes) (DIDI-HUBERMAN, 2007, p. 9).

En cada ocasión en que se enfrenta una imagen, se pone en cuestión todo el saber, pues este hecho es capaz de modificar toda una visión de mundo al tiempo que renovar el lenguaje y el modo de enfrentarlo.

La historia del arte que Didi-Huberman examina-la que va de Plinio y Vasari hasta Winckelmann y Lessing-, está caracterizada por una nostalgia ante la "declinación" de las artes y una historia que aparece como un gran relato (grand récit) determinado y vectorizado. Es esa historia del arte que, como la historia del pensamiento en general, se quiebra con Nietzsche, a partir de quien el discurso histórico se encuentra criticado y comienza a ser deconstruido y recompuesto sobre modelos complejos de temporalidad. En este sentido, Warburg pone en movimiento cierta visión de las cosas, desplazándolas en el espacio y el tiempo a partir de la noción de supervivencia, encontrando en estos movimientos críticos de la representación y el símbolo, el síntoma, un evento que encierra símbolos contradictorios, que muestra significados opuestos y pone en crisis modelos convencionales de representación. En estas nociones, aparece velada, además, la idea de que las supervivencias son como fantasmas que sustentan una revolución que, para DidiHuberman, se lleva a cabo en todos los ámbitos del conocimiento: en la pintura (Picasso y los dadaístas, por ejemplo), en el literario (James Joyce), en el de la estética (Carl Einstein y Georges Bataille), en el campo cinematográfico (Sergei Eisenstein, para mencionar sólo uno). 
La idea de representación histórica que está por detrás de estas ideas se caracteriza por ser aleatoria, vital y rítmica. Estas son las tres notas que Didi-Huberman atribuye a este conocimiento por el montaje. El atlas Mnemosyne de Warburg está construido con esta lógica en la que la arbitrariedad y el azar se combinan para construir un discurso que es a la vez estético, histórico y político. Es la misma relación entre las imágenes la que va generando efectos de conocimiento a partir de las similitudes y diferencias, de ciertas operaciones que el lector/espectador debe hacer y de la propia apertura a la inteligibilidad que la imagen por sí sola produce. En este sentido, Didi-Huberman apela a un "conocimiento por los montajes" (connaissance par les montages) desde el momento en que todo objeto (o evento) social o histórico se constituye como un solapamiento o entrelazamiento de elementos heterogéneos que producen un nuevo sentido. Podrían incluso tener una función profética, al concebir a la imagen como una suerte de síntoma de una crisis por venir.

En la imagen, hay un cúmulo de referencias memoriales que se entrechocan entre sí, la constituyen y ponen en crisis la representación que ofrece. Didi-Huberman asegura que así funciona gran parte de la historia del arte occidental. Teniendo en cuenta estas consideraciones sobre las imágenes, es posible ver una dimensión antropológica que sobrevive en ellas:

\begin{abstract}
Cada imagen debe pensarse como un montaje de lugares y tiempos diferentes, incluso contradictorios. Es por esto que el Atlas de Warburg (...) aparecía como un modelo de método, una matriz a desarrollar. El montaje intrínseco en todo evento podría ser, desde el punto de vista histórico, nombrado una anacronía o una heterocronía. El anacronismo sería entonces el conocimiento necesario de estas complejidades, de estas complejidades temporales. Ante una imagen, no hay que preguntarse solamente qué historia documenta y de qué historia es contemporánea, sino también qué memoria en ella se sedimenta, de qué reprimido es el retorno (DIDI-HUBERMAN, 2007, p. 12).
\end{abstract}

Esta sedimentación memorial de la historia que Warburg y Benjamin contemplaban en el seno de su comprensión de la lógica histórica es un punto de partida para leer las imágenes al tiempo que éstas son la plataforma adecuada para atender a la legibilidad de la historia.

Supervivencia y anacronismo pueden resultar grandes aliados al momento de pensar la extrapolación del archivo warburgiano al ámbito cinematográfico con sus especificidades. Ante un inmenso y rizomático archivo de imágenes heterogéneas de difícil dominio, Didi-Huberman plantea que los problemas propios del archivo se pueden contrarrestar con la imaginación y el montaje. Es esta última la herramienta fundamental a partir de la cual se puede producir una interpretación cultural e histórica, "retrospectiva y prospectiva -esencialmente, imaginativa" (DIDI-HUBERMAN, 2008, p. 5).

En la lógica warburgiana, cada imagen se convierte en algo que -como parte de un todo- constituye un fotograma en un gigantesco tramo de material fílmico. Es la imagen la que puede dislocar el todo e interrumpir y, con esta disrupción, modificar, revelar y solicitar las narrativas predecibles de la historia del arte. Ésta se consideraba atada a líneas de organización reductivas que obligaban a pensar que había una narrativa que delineaba el modo en que el arte cambiaba y se desarrollaba a lo largo de los diferentes períodos. 
Es a la luz de la lógica warburgiana para pensar la historia del arte que es posible concebir una interrupción del continuum que limita la posibilidad de voces alternativas y formas dinámicas de pensar la historia, la historia del arte y la función del historiador. Esta perspectiva proporciona elementos para leer textos históricos y artísticos a fin de hacer aparecer una teoría del arte imagística que dispone a la obra de arte en una historia consistente, en una serie de imágenes fracturadas, que conceptualizan la historia como si fuera una película.

Es especialmente Michaud (2006) quien profundiza sobre las hipótesis de Warburg en un terreno que es sugerente a la hora de abordar la imagen en la desmaterialización de la historia, como lo es el cine. Aunque de traducción difícil, la noción de "Zwischenreich" puede ser interesante para pensar esta lógica intersticial que plantea la historia warburgiana. Literalmente, sería "un reino-entre" o "reino del entre" que induce a pensar en aquello que se produce entre las imágenes, en los espacios intermedios, en el intervalo. De acuerdo con este principio, Mnemosyne podría ser pensada como una iconología de los intervalos, en la que Warburg construye una memoria topográfica de la historia y el arte. Se trata de una iconología que se preocupa no por la significación de las figuras, sino por la relación que esas figuras comportan entre ellas en un dispositivo visual autónomo. Michaud sugiere, además, que las claves para comprender esa iconología de los intervalos planteada por Warburg son las nociones de introspección y montaje. Cada plancha inaugura una constelación (siguiendo la terminología del historiador del arte Werner Hofmann). Disponiendo las imágenes sobre los paneles de su atlas, Warburg pretende activar las propiedades dinámicas que estaban latentes en las imágenes mientras permanecían aisladas unas de otras. Para elaborar esta técnica de activación se inspira en un concepto forjado por el psicólogo alemán Richard Semon, quien define la memoria como la función encargada de preservar y transmitir la energía en el tiempo y que permite que se la reconduzca a un hecho del pasado: todo evento que afecta al ser vivo deja una huella en la memoria, a la que Semon denomina "engrama" y que describe como la reproducción de un original. Las imágenes de Mnemosyne son "engramas" capaces de hacer resurgir una experiencia del pasado en una configuración espacial; conforman un archivo de figuras arcaicas sedimentadas por la cultura moderna que recuperan su energía expresiva original. Como los engramas de Semon, las imágenes de las planchas de Mnemosyne son reproducciones fotográficas, es decir, literalmente -como señala Michaud- son "fotogramas".

Las planchas de Warburg se articulan a partir de la comparación y el découpage. Funcionan a la manera de secuencias discontinuas que exhiben su verdadera condición solamente a partir de su encadenamiento sobre un dispositivo. Los paneles no funcionan tanto como cuadros estáticos, sino más bien como pantallas que reproducen en simultaneidad los fenómenos que el cine produce en la sucesión. Michaud encuentra que los intentos warburgianos se pueden vincular con las ciencias humanas de fines del siglo XIX, pero especula con que posiblemente sea en la historia del cine contemporáneo donde es posible encontrar un equivalente más adecuado de la puesta en tensión de las imágenes y la puesta en movimiento de las superficies que Warburg produce en Mnemosyne: 
Jean-Luc Godard, en las Histoire(s) du cinéma, buscando "aproximar las cosas que no están dispuestas a hacerlo", trabaja el material fílmico como Warburg el suyo en la historia del arte, haciendo surgir el sentido de actualización de las imágenes a partir de la revelación recíproca que sólo permite la técnica del montaje. En sus Histoire(s), quedescriben, de una forma muy mallarmeana, "una saturación de signos magníficos que se bañan en la luz de su ausencia de explicación”, Godard busca seguir las huellas de la migración de las imágenes a través del tiempo del cine usando la imagen misma como un revelador descriptivo y crítico: las sobreimpresiones y las yuxtaposiciones que el video permite tienen la misma función que la fragmentación de la cabeza de Holopherne y de la golfa esbozada por Warburg ${ }^{1}$ y responde a la superposición propuesta por Gordard de la silueta de Lilian Gish, azorada en la niebla en Huérfanas de la tormenta (David W. Griffith, 1921) y una histérica de Charcot (MICHAUD, 2006, p. 22).

La historia del arte entendida como historia de las imágenes y la historia del cine se abren a una dimensión no puramente artística (o no exclusivamente) vinculada al tiempo. Tal como lo explica Michaud, el atlas es un instrumento de orientación destinado a seguir la migración de las figuras a lo largo de la historia de las representaciones hasta los estratos más prosaicos de la cultura moderna. Rechaza deliberadamente las jerarquías normativas del arte habilitando una definición extra-artística de las imágenes.

En el archivo de Warburg, la fotografía no es simplemente un soporte ilustrativo, sino un "equivalente plástico general al que son llevadas todas las figuras antes de ser dispuestas en el espacio de la plancha" (MICHAUD, 2006, p. 42). En primer lugar, la operación fotográfica unifica los objetos de naturaleza diversa; luego, son ensamblados sobre las planchas nuevamente fotografiadas para crear una imagen única que, finalmente, se inserta en una seguidilla destinada a tomar la forma de un libro interminable que da cuenta de un conocimiento en movimiento. El atlas no se limita a describir las migraciones de las imágenes a través de la historia de las representaciones, sino que las reproduce introduciendo en la historia del arte una forma de pensamiento "archivista" que utiliza las figuras para articular efectos más que significaciones.

\section{PATHOSFORMELN CINEMATOGRÁFICAS}

Sesenta años después de Warburg, Jean-Luc Godard planteaba en las Histoire $(s) d u$ cinéma (1988-1998) una suerte de atlas cinematográfico sobre la historia del siglo a partir de un uso similar del montaje. A partir de ambas experiencias, se comprueba un intento desmaterializador de la historia, que ya no concibe diferencia entre sincronía y sucesión, sino que piensa a la historia como superficie que escapa a la lógica progresiva y propone la relación entre pasado y presente a partir de la condición de recuperar las voces inaudibles en los relatos hegemónicos. Esta relación entre historia, espacio y tiempo puede revisarse especialmente en dos trabajos herederos de las Histoire(s): The Old Place (1999) y Dans le Noir du temps (2002). Se trata de ejercicios sobre el tiempo y epifanías espaciales sobre el nexo entre literatura, música, pintura e historia del arte, para entrevistar los sueños y horrores del siglo.

\footnotetext{
${ }^{1}$ La referencia corresponde a la plancha 77 del Atlas Mnemosyne.
} 
El primero de estos trabajos, realizado en colaboración con Anne-Marie Miéville, fue encargado por el MoMA de Nueva York para pensar el rol de las artes en el enfrentamiento con el fin del siglo. Con este ensayo, los cineastas vuelven al videoespectáculo para hacer aparecer a Simone de Beauvoir, Thomas Mann, Henri Bergson y Jorge Luis Borges, entre muchos otros. El segundo film forma parte de la película colectiva Ten Minutes Older: The Cello y constituye una suerte de poema sobre "las últimas imágenes", imágenes arrancadas de su contexto para iluminar momentáneamente la pantalla y volver a sumirse en la oscuridad resultando, de algún modo, una metáfora del funcionamiento propiamente cinematográfico.

Tanto en los ejercicios godardianos como en la premisa de Warburg a partir de la cual leerlos, la historia se proyecta sobre lazos afectivos entre la materialidad de las imágenes y la inmaterialidad de las relaciones mentales que se producen a partir de ellas. En ambos casos, es el montaje el que habilita un espacio de pensamiento (una suerte de Denkraum warburgiano) a partir de la descontextualiación y la relocalización, que parece operar en ambos como un mecanismo de resistencia a las historias convencionales. La potencia heurística de la lógica intersticial warburgiana permite atravesar los films de Godard rastreando las conexiones afectivas que le permiten medirse con la historia y las supervivencias que se yuxtaponen con urgencia "anacronizante".

La imagen-video se transforma en un entramado a partir del cual rastrear las motivaciones afectivas que escanden la Bildraum godardiana desde Auschwitz hasta la guerra de Argelia pasando por el Mateo de Pasolini para terminar imaginando un museo como André Malraux, en un contexto donde la estetización de la vida y la tecnología de la guerra traban indisoluble relación. En ambos casos, mostrar la potencia de los nexos afectivos implica reconocer su intensidad en la economía de las imágenes que configuran la realidad contemporánea. El arte en general y el cine en particular constituyen inextricables campos de la política y la vida cotidiana donde se pone a prueba la importancia del acercamiento afectivo.

Si bien el principio archivístico de Godard y Warburg es diferente, podría decirse que se sostiene en ambos casos en que las imágenes son "afectos congelados en el tiempo y el espacio" (O’SULLIVAN, 2001, p. 26), a la espera de ser activados por el espectador, es decir, dan lugar a la aparición de un acontecimiento, de una experiencia: una búsqueda de cierta experiencia histórica en Warburg y una reflexión sobre la vocación política del cine en Godard. En ambos, el arte ejerce una función crítica a partir de algo diferente de la preocupación semántica por la estabilización del sentido, es decir, "un portal, un punto de acceso a otro mundo (nuestro mundo experienciado de modo diferente), un mundo de impermanencia e interpenetración, un mundo molecular del devenir" (O’SULLIVAN, 2001, p. 28).

Las Pathosformeln constituyen en Warburg la clave para desvelar conexiones entre el pasado, la memoria y la disrupción. Explorar el archivo a partir de estas conexiones afectivas implica en Godard interrogar la cognición propiciada por la aisthesis, una combinación de afectos e intensidades. El montaje constituye el principio que pone en funcionamiento estas relaciones. Así parece haber sido en las Histoire(s) du cinéma, con las que Godard se empeña en profanar las historiografías hegemónicas para "servirse" de la historia del cine y reescribir performativamente su propia historia del siglo. En las ocho 
entregas de Histoire(s) du cinéma (1988-1998) se habilitan las yuxtaposiciones, los contrastes, los montajes paralelos, las interrupciones, los abusos de la imagen, entre otras operaciones que los relatos profesionales del pasado no siempre se pueden permitir. Godard vuelve evidente la necesidad de que el cine "se mire en su propio pasado" (AMADO, 2009, párr. 2) y configura una matriz para dar cuenta de la/su memoria del siglo XX. En el tercer capítulo, "La moneda de lo absoluto", hace explícita la herencia estética de Malraux. Así como éste consideraba a la cultura una colección de obras sacadas de contexto y puesta en un diálogo infinito de formas, Godard propone museos imaginarios que le permiten volver a alinear los objetos en una operación motivada por el afecto, los deseos y los reproches hechos a la historia.

También Warburg ponía en funcionamiento el "museo imaginario" relevando a las imágenes de su función original apelando a lo que Malraux llamó metamorfosis, que desarmaban las relaciones de uso y propiedad. Naturalmente, el verdadero lugar para el museo imaginario era para Malraux el espacio de la mente, un espacio cargado de intensidades que movilizan afectos y emociones para quien asiste a la configuración de series imprecisas y siempre cambiantes. Sin embargo, no parece extraño asumir el intento de concretizarlo a través de la materialidad en diálogo con un espacio cultural complejo en el que la institucionalización de la imagen está ligada a discursos hegemónicos que se apropian de su funcionamiento y operatividad de la imagen. Lo tenía claro Malraux cuando proponía el museo imaginario como resistencia, como inapropiabilidad respecto de los discursos del poder.

En su libro Performing the Archive (2009), Simone Osthoff asegura que se asiste a un "cambio ontológico" en la noción de archivo, pues se estaría pasando del archivo como un "repositorio de documentos" al archivo "como una dinámica y una herramienta de producción generativa" (OSTHOFF, 2009, p. 11). Para la autora, este cambio se puede datar a partir de las "disrupciones actuales de la representación producidas por los artistas, críticos y curadores contemporáneos" (p. 11) y se produce por lo que caracteriza como una contaminación entre obra de arte y documentación, que obliga a pensar que la teoría y la historia no están ni completamente afuera ni completamente adentro del arte, y que pueden funcionar como esferas dinámicas. En este sentido, el archivo ya no puede pensarse como un "archivo retroactivo, sino más frecuentemente como uno generativo" (Osthoff 2009, 12) en el que proliferan los elementos performativos y visuales que constituyen un desafío metodológico para la historia.

El paradigma del archivo encuentra en La arqueología del saber (1969) de Michel Foucault su prehistoria ineludible. Allí se establecen los fundamentos contemporáneos sobre la noción de archivo: no se trata ni de un conjunto de documentos, registros o datos que se guardan como memoria o testimonios sobre el pasado, sino que es para Foucault lo que permite establecer la legalidad de lo que puede ser dicho. Los enunciados pueden ser pronunciados en tanto acontecimientos singulares a partir de las regularidades instauradas por el archivo, es decir, las reglas que caracterizan y posibilitan la práctica discursiva. Los documentos del archivo no deben ser estrictamente -o exclusivamenteinterpretados, sino que deben interrogar lo dicho en su propia existencia, a fin de construir la historia en función de "episodios del pasado como si fueran del presente" (Foucault 1969, 234-235). 
En el "giro archivístico" (archival turn) preconizado por Hal Foster -que constituye precisamente una crítica al archivo entendido en los términos de Foucault-, los artistas descontextualizan imágenes y objetos y conforman obras incluso como "contra-archivo privado que emerge de la vida cotidiana y la cultura popular" (HIRSCH, 2012, p. 227). Esta descontextualización parece ser precisamente la operación fundamental puesta en funcionamiento en los trabajos de Godard. El cineasta hace de la desconexión entre imagen, texto y sonido una constante de transformación de las citas cinematográficas y literarias, produciendo una espacialidad crítica nueva, que interrumpe tanto la referencia del homenaje como la potencia de representación convencional, que ya no se guía por una temporalidad progresiva, sino por una lógica ligada a la contingencia afectiva y la fragmentación.

Refiriéndose a las estrategias godardianas, Didi-Huberman sugiere que los "pasados citados" por el cineasta dan cuenta a la vez de un gesto respetuoso y uno irrespetuoso, "constituyen al mismo tiempo un acto de referencia y un acto de irreverencia" (DIDI-HUBERMAN, 2015, p. 15). Se trata de una cita "porque no se inventa nada" -insiste el autor-, pero una que se transforma. Esta transformación implica tanto una apelación a la autoridad como un rechazo de ella y ambas conforman una coherencia estética que parece apoyada sobre la potencia de la "libre circulación de las imágenes y las palabras que las Histoire(s) du cinéma llevarán hasta la incandescencia" (DIDI-HUBERMAN, 2015, p. 19). Se trata de una transformación de la imagen en afecto, en pura intensidad que (des)configura toda idea de autoridad, posibilitando un espacio de pensamiento que no clausura en sentidos, sino que hace de la pausa y la repetición la estructura permanente del significante.

Godard elabora en estos trabajos archivos de sus propias conexiones afectivas con los acontecimientos. De este modo, el abordaje de la historia adquiere un carácter de autoconstrucción, pues el cineasta indaga tanto sobre el uso del material para construir la propia memoria, como sobre la producción del archivo para articular la historia y configurarse a sí mismo como cineasta. Los films poseen las características que normalmente se atribuye a los archivos visuales, esto es, se convierten en huellas del tiempo, ordenan espacios de persistencia del pasado hasta su cristalización, modulan migraciones mediáticas de la historia en diversos soportes. No obstante, la particularidad del archivo godardiano está en que el sustrato no es (sólo) la espectralidad de la memoria y los recuerdos, sino la materialidad de la imagen y su capacidad de sedimentación.

Estos trabajos son el producto modélico arrojado por la "era del archivo" que impone al cine contemporáneo una suerte de "hechizo", según la propuesta de Vicente Sánchez-Biosca (SÁNCHEZ-BIOSCA, 2014, p. 96). Sus series proponen una superficie fascinada por el material que el pasado arroja con sus lagunas y fisuras, y las incertezas propias de cualquier narración sobre el tiempo. Por eso cabe preguntarse ¿dónde está la potencia archivística de Godard? ¿En la reutilización de las imágenes de la historia del cine para re-narrar la historia del siglo? ¿En la lectura de la historia a través del cine? ¿O en la lectura del cine a partir del pasado?

Benjamin Buchloh señala que el archivo implica "una creación artística basada en una secuencia mecánica, en una repetitiva letanía sin fin de la reproducción, que desarrolla con estricto rigor formal y coherencia estructural una 'estética de organización 
legal-administrativa"" (GUASCH, 2011, p. 9). Leer los archivos godardianos en esta clave implica comprender que no se trata de "asignar" un lugar en la colección o depositar algo en coordenadas de clasificación, sino consignar, agrupar, unificar, identificar, clasificar y configurar un corpus para leer la relación entre cine, historia y afectos de acuerdo a unas particulares relaciones de temporalidad cuyo único fundamento está en las intensidades que se producen entre imagen y lectura.

Los trabajos de Godard permiten volver sobre algunos de los problemas de la representación histórica en un doble sentido: en primer lugar, al pensarlos como archivo, es decir, partiendo del supuesto de la relación entre las huellas de los acontecimientos y los poderes hegemónicos que tienen la capacidad de activar o desactivar su potencia para configurar relatos sobre la historia; en segundo lugar, al proponer una deconstrucción del archivo en su trabajo con "imágenes-fuentes" en el mismo acto de serialización. Si frente al problema de las fuentes, todo historiador debe evaluar las estrategias para abordarlas, en el caso del cineasta, son sometidas al doble proceso de archivo descentrado y teorización en una autobiografía visual: las "historias" de Godard son historias de "cinemoi" a través de las cuales conjura la deuda del cine con la historia y la reescribe a expensas de la primera persona del singular y "el sujeto esencial considerado como una ilusión" (GUASCH, 2009, p. 57) inscripto en el modelo del lugar, la localización adonde van a parar las palabras y las cosas.

Warburg describe Mnemosyne como una "historia del arte sin texto", que comprende 1000 fotografías ordenadas según un sentido de afinidad. Desde piezas del Renacimiento hasta fotografías de publicidades de las primeras décadas del siglo XX, se "apilan" como los estratos del tiempo sobre un dispositivo de almacenamiento de la memoria socio-cultural. Estas imágenes "no estructura[n] una historia discursiva, sino imágenes o pathosformel, en tanto que formas -formulae- portadoras de sentimientos pathos-, que funcionan como representaciones visuales y como maneras de pensar, sentir y concebir la realidad" (GUASCH, 2011, pp. 24-25).

Buchloh sugiere que el de Warburg es el más importante ejemplo de una tendencia anti-positivista de la historia. En este sentido, Mnemosyne sería

\footnotetext{
un modelo mnemónico en el que el pensamiento humanista de Europa occidental reconocería una vez más, tal vez por última vez, sus orígenes, y rastrearía sus continuidades latentes en el presente alcanzando espacialmente a través de los confines de la cultura humanista europea y situándose temporalmente en los parámetros de la historia europea desde la antigüedad clásica hasta el presente (BUCHLOH, 2004, p. 122).
}

El archivo warburgiano parece hacer especial hincapié en la construcción de la memoria histórica colectiva focalizando en la relación entre lo mnemónico y lo traumático. Este vínculo puede pensarse a partir de una particular afinidad con el ejercicio de Godard, quien configura la relación entre la historia y el siglo XX a partir del devenir catastrófico. Estos archivos componen heterogeneidades y discontinuidades sin el establecimiento preciso de cronologías o linealidades. Ambas resultan de estructuras descentradas en las que no se eluden ni las contradicciones, ni las series evidentes. A partir de un modelo de temporalidad que entrama supervivencias, Warburg exige leer el anacronismo en la historia y la superposición de tiempos que se contradicen como síntomas a partir de imágenes que desvelan relatos no-convencionales del pasado. 
En Warburg, la imagen se revela como elemento histórico decisivo, como "lugar de la actividad cognitiva humana en su confrontación vital con el pasado" (AGAMBEN, 2007, p. 185). Siguiendo estas intuiciones, es posible asumir que Warburg transformó la imagen en un "elemento decisivamente histórico y dinámico" (AGAMBEN, 2001, p. 52) y que una de sus mayores aspiraciones haya sido comprender y describir las energías inherentes a las imágenes de la cultura, esto es, las energías "guardadas" en esas imágenes, que esperan ser revividas en la fantasía sobre otras épocas, re-afectadas por las vivencias de distintos tiempos.

La gramática (y la técnica) propia del cine hace imposible concebir la temporalidad de la imagen más que a partir de la interrupción. De modo similar al intento de Warburg, las imágenes de Godard dislocan intempestivamente el presente con mecanismos puramente imaginales de intelección del pasado. La temporalidad que construye el archivo de Godard no es del orden de la sucesión, sino de un tipo de montaje. En esta clave, así como la estrategia warburgiana pretende desocultar la lógica dominante en la historia teleológica a fin de consolidar un relato basado en las motivaciones emocionales del historiador o el artista, Godard repiensa el vínculo entre cine y filosofía reafirmando el gesto cinematográfico como destino privilegiado de la memoria histórica.

El archivo toma la forma de un ensayo donde imagen y afecto configuran un dispositivo que deviene un "montaje de proposiciones" - tal el rasgo fundamental que Antonio Weinrichter atribuye al film-ensayo. Estas proposiciones -imágenes solas o imágenes en una tensión permanente con el texto- configuran lo que con Didi-Huberman se podría definir como una historia del arte (cinematográfico) radical, es decir, una que diluye las fronteras disciplinares para disponer un espacio-tiempo sobre la idea eisensteniana de montaje, esto es, a partir del choque y el conflicto.

Sergei Eisenstein proponía una relación entre la toma y el montaje desde la colisión. En efecto, aseguraba que el sentido se producía por el choque entre dos piezas "dado que la base de todo arte es el conflicto (una transformación 'imaginista' del principio dialéctico). La toma... debe ser considerada desde el punto de vista del conflicto" (EISENSTEIN, 1949, pp. 37-38). The Old Place y Dans le Noir du temps parecen herederas de un uso similar del montaje y arremeten contra una convencional relación espacio/tiempo. Dans le noir du temps encierra once epifanías que entretejen una trama temporal que captura una/la "última imagen" -los últimos minutos de la juventud, del coraje, del pensamiento, del amor, entre otros- y pone en tensión el espacio audiovisual que surge de los ejercicios de The Old Place. Como sugiere Didi-Huberman para las Histoire(s), en estos casos también es posible leer el trabajo de figurabilidad que se pone en funcionamiento. Es decir, un trabajo "que engendra por así decir un estado de 'revolución permanente' donde cada imagen devendrá capaz de criticar a todas las precedentes" (DIDI-HUBERMAN, 2015, p. 45). Este principio de figurabilidad permite rastrear las variadas formas que adquiere lo político en las imágenes. El agonismo y su inherente irresolución constituyen las operaciones principales de un montaje que se sustenta en la tensión entre las imágenes, en el vacío que propicia el pensamiento, en la intensidad de la emoción.

Godard quiebra con una concepción lineal de la historia proponiendo un archivo fragmentario a partir de la manipulación de la imagen, el montaje de heterogeneidades y 
el intento deliberado de volver a contar la historia de los trazos que se pierden en las historizaciones hegemónicas. Los ejercicios de The Old Place lo hacen con una colección de fragmentos que apuntan a saber si el arte es leyenda o realidad. Para abordar la cuestión, Godard va de las viejas estrellas a las memorias de Van Gogh, pasando por Boltanski, la guerra de Yugoslavia y Goya preguntándose si deben -y de qué modocontinuar entre la decepción y la magia, la utopías y el enamoramiento, las películas hechas con un dólar, el arte como leyenda, la Muchacha con pendiente de perla de Vermeer (1665), los films de Griffith y la pasión de Cristo. Godard se pregunta por el destino de las cosas a partir de los objetos de una casa que portan su temporalidad, los muebles y el jardín benjaminiano como apelación al tiempo es la que hace desear el pasado para hacer algo con él. Por eso pasan Kosovo, Argelia y hasta la Italia del Renacimiento tanto como las 19 personas que estuvieron presentes en la crucifixión de Cristo y los dos mil millones que acudieron a la Copa del Mundo.

El ángel de la historia atraviesa el "No tresspassing" de El ciudadano (Citizen Kane, 1941) de Orson Welles para vincularlo semánticamente con un cartel que amenaza: "Prohibido entrar. Propiedad del Estado". Por eso en Dans le noir du temps se intenta atrapar los últimos minutos de la libertad y el pensamiento, desde la memoria con las topadoras en Auschwitz, el silencio imposible de guardar en la escena de la tortura en La batalla de Argelia (La battaglia di Algeri, Gillo Pontecorvo, 1966), las últimas imágenes del miedo y la guerra de Yugoslavia, las de la eternidad de El evangelio según San Mateo (Il vangelo secondo Matteo, 1964) de Pier Paolo Pasolini. Godard encuentra en estas imágenes los últimos minutos de la vida, que no se vinculan a la muerte, sino al cine, su cine. Por eso aparecen imágenes de Vivir su vida (Vivre sa vie: Film en douze tableaux, 1962) para dar lugar a la tela blanca de una performance que se deshace en su propio mecanismo como el cine y la historia referidos en estas páginas.

Una lógica intersticial warburgiana gobierna el montaje de Godard. Este se configura a partir de supervivencias, es decir, de imágenes del "vivir-después", esto es, después de su aparición original; después de su pasaje por la memoria con urgencia "anacronizante"; después de la desterritorialización de la imagen y el tiempo como paradójica indicación de la historia.

Warburg proponía rearmar la historia restituyendo "timbres de voz inaudibles", voces replegadas en los pliegues de los archivos canonizados. Como en los films de Godard, se produce una reaparición fantasmal en la que las imágenes sobreviven a la sedimentación antropológica que las hizo devenir parciales o inexistentes por parte de cierta mirada sobre la historia. Lo que hace Warburg es reconstruir un "pueblo de fantasmas" con huellas apenas visibles, diseminadas como los fantasmas de Godard. Warburg quiere activar en las planchas de su atlas "los efectos latentes en las imágenes, organizando su confrontación siempre sobre fondos negros, que utiliza como 'medio conductor"” (AMADO, 2009, párr. 9), logrando una iconografía del afecto, del pathos que resiste la historización. La supuesta homogeneidad de la historia se disuelve en una cartografía afectiva plagada de intensidades que obliga a una mirada sincrónica, ligada a la simultaneidad del estallido más que a la sucesión del relato.

Mnemosyne había sido considerado en su época como un intento fundador de conciliar una visión histórica y una visión filosófica de las imágenes. El proyecto de un 
atlas de imágenes remitía a la idea de las Pathosformel como formas arquetípicas ligadas a la expresión del pathos (dolor, deseo, duelo). Estos gestos que traducen las pasiones (brazos levantados, bocas abiertas, torsiones del cuerpo, etc.) resurgen de época en época y constituyen un "fondo gestual" del que se alimentan los artistas. Con el montaje, la "bella preocupación” de las Histoire(s), Godard también restituye el movimiento a las expresiones patéticas de una historia tan contingente como las voces que la cuentan. Tal como Warburg la entiende, la supervivencia de esos afectos conduce a pensar que el presente lleva la signatura de múltiples pasados haciendo evidente la indestructibilidad del tiempo sobre las formas y los espacios a los que se puede acceder desde la imagen. Se trata de abrir en la actualidad de una imagen "la brecha de las supervivencias" (DIDIHUBERMAN, 2009, 51) para oír la voz de los fantasmas que malviven en los objetos históricos y las pulsiones del futuro.

\section{ÚLTIMOS AFECTOS DE ESTE ARCHIVO}

Warburg sustituye el modelo natural de los ciclos "vida y muerte" y "grandeza y decadencia" por un modelo simbólico, un modelo cultural de la historia en el cual los tiempos se expresan por "estratos, bloques, híbridos, rizomas, complejidades específicas, retornos inesperados y objetivos siempre desbaratados" (DIDI-HUBERMAN, 2009, pp. 24-25). Reemplaza los modelos anteriores por uno de la historia al que llama "fantasmal", dado que los tiempos no se montan sobre la transmisión académica, sino por obsesiones, supervivencias y reapariciones de las formas, es decir, "por no-saberes, por impensados, por inconscientes del tiempo" (2009, p. 25). Se trata de un modelo psíquico en el sentido de la posibilidad de descomposición teórico. Este giro en el pensamiento de la historia y el arte produce una modificación radical en el modo de situarse frente a las imágenes y el tiempo. La historia del arte se inquieta convirtiéndose en "un torbellino en el río de la disciplina, un torbellino - un momento-perturbador- más allá del cual el curso de las cosas se inflexiona e incluso se trastorna en su profundidad" (DIDI-HUBERMAN, 2009, p. 26).

El atlas Mnemosyne constituye un archivo visual que repiensa la historia del arte en la forma de un archivo icónico articulado sobre heterogeneidades y discontinuidades, en base al valor intrínseco de la imagen y el valor relacional de la que se ha "obviado cualquier jerarquía, límite o frontera de orden cronológico o temático -aunque no de significación- que responde a un pensamiento histórico 'subjetivo' y en buena medida rizomático, activado desde el presente" (GUASCH, 2011, p. 25).

Existe cierto acuerdo en que la revitalización de las ideas de Warburg se liga a la desilusión, en el siglo XX, causada por las mayor parte de las narrativas históricas. En este contexto, sus intuiciones proveen una perspectiva que combina el estudio de los microfenómenos y la información detallada sobre períodos breves de tiempo, a la vez que reafirma la articulación de modelos explicativos (provenientes de la sociología y la antropología) con aproximaciones empíricas ligadas a las imágenes.

En la concepción warburgiana del arte que subyace a estas consideraciones radica el supuesto de que la obra no es monumento, sino un documento que se abre a la interpretación permanente, es decir, una "obra abierta" que elide su pertenencia al tiempo 
cronológico. El método de Warburg ayuda a pensar el abordaje de la imagen como caracterizado por un rechazo de todo método estilístico-formal convencional, identificándolo más bien con un desplazamiento del foco de interés desde la historia de los estilos a la valoración de "los aspectos programáticos e iconográficos de la obra de arte, tal como resultan del estudio de las fuentes literarias y del examen de la tradición cultural" (AGAMBEN, 2007, p. 158). Lo esencial de una aproximación como la de Warburg es advertir que un acercamiento desde el punto de vista formal es insuficiente para conocer la mente de un pintor del Renacimiento. De ahí también que el concepto de Pathosformel que implica la indistinguibilidad entre forma y contenido, pues "designa un entramado indisoluble de carga emotiva y fórmula iconográfica" $\mathrm{y}$, además, "suficiente testimonio de que su pensamiento no se deja de ninguna manera interpretar en términos de una contraposición tan poco genuina como la forma/contenido, o la de historia de los estilos/historia de la cultura" (AGAMBEN, 2007, p. 159). Se trata de un nuevo modo de hacer historia del arte, una dilución de la disciplina tradicional en documentos e imagen.

Con esta desmaterilización de la historia queda planteado el desafío de tirar abajo el principio fundamental del historiador ingenuo -el de no "proyectar" realidades de un tiempo actual sobre realidades pasadas intentando comprender las imágenes en una concordancia eucrónica. Pensando en los dispositivos planteados por Warburg y Godard, es posible apropiarse de la propuesta de Didi-Huberman quien sugiere taxativamente no rechazar el anacronismo en el estudio de las imágenes y pensar el sentido histórico como un tejido complejo en el que las imágenes se proyectan, dispersan, diseminan, entrecruzan y solidarizan.

Didi-Huberman llama "soberanía del anacronismo" al intento de atravesar las imágenes con herramientas que no concuerdan con el momento de producción de la obra reubicándola en una temporalidad que no rehúye de nuevas asociaciones y contextos. Esta descontextualización permite que el historiador se acerque al pasado (contenido en una imagen) no sólo de modo "eucrónico" -porque entonces perdería el sentido del gesto artístico que configuró esa obra en el entrecruzamiento de dimensiones heterogéneas del tiempo-. El anacronismo es, entonces, deseable cuando la "ida al pasado" es insuficiente y constituye muchas veces un obstáculo para la comprensión de la imagen. En este sentido, quedarse en la dimensión de "el artista y su tiempo" es perderse las manipulaciones del tiempo con las que pudo haber sido construida la obra. Examinar la imagen en una perspectiva anacrónica -“el artista contra su tiempo"- permite trazar constelaciones temporales que escapan a la linealidad y la homogeneidad y se apoyan en la discontinuidad de permanentes presentes y, para decirlo con Benjamin, de permanentes "ahoras":

Para acceder a los múltiples tiempos estratificados, a las supervivencias, a las largas duraciones del más-que-pasado mnésico, es necesario el más-que-presente de un acto: un choque, un desgarramiento del velo, una irrupción o aparición del tiempo, aquello de lo cual hablaron tan bien Proust y Benjamin bajo la denominación de 'memoria involuntaria' (DIDIHUBERMAN, 2007, pp. 23-24).

En esta valoración del anacronismo, se vuelve a hacer presente la matriz conceptual que guía este trabajo, el tiempo de la memoria involuntaria sumado a la ineludible 
determinación histórica de la imagen sobre una desterritorialización de la estética y la filosofía de la historia. Esto implica pensar a la imagen como el punto de reunión de múltiples tiempos y voluntades y a la imagen cinematográfica como la instauración de la duración a relatos sobre la articulación de pasado, presente y futuro.

Godard y Warburg podrían pensarse como el coleccionista de Benjamin que inaugura siempre el tiempo en direccionalidades múltiples y movibles: "Lo que su arqueología material actualiza no es otra cosa que una estructura mítica y genealógica: una estructura de supervivencias y anacronismos (donde todos los tiempos genealógicos conviven en el mismo presente)" (DIDI-HUBERMAN, 2007, p. 143). Las cosas no transforman su tiempo en un pasado fijo y desaparecido, sino que se transforman en supervivencias. Los archivos de Godard y Warburg hacen de la supervivencia un concepto en el que se juega el fondo último de la historicidad y sienta las bases para que la comprensión histórica en su conjunto pueda ser concebida como una supervivencia.

Como todo archivo tiene una última imagen, podría volverse sobre las láminas 78 y 79 de Mnemosyne. Allí están concentradas la mayoría de las referencias waburgrianas a su contemporaneidad sugiriendo al espectador que se (des)oriente libremente entre la Misa de Bolsena y el pacto entre el fascismo y la iglesia católica pasando por los primeros pogromos y artistas del Renacimiento italiano. Warburg propone atravesar una experiencia itinerante, circulando a través de la historia que se abre delante de sus ojos en imágenes que proponen metamorfosis, inversiones, trasvestimientos crípticos y alusiones explícitas. El intersticio warburgiano propone un pasaje complejo de la ferocidad del ritual del sacrificio a la sublimación de la eucaristía, de las estampas propagandísticas de la cultura popular indicando la polaridad entre lo lógico-racional y lo mágico-patético.

Godard, por su parte, elige las últimas imágenes. Allí se combinan esos instantes que se encienden y sumen en la bruma de un mecanismo propiamente tan mágico y patético como la revisión de una historia del arte que se auto-construye en cada espectador.

\section{REFERÊNCIAS}

AGAMBEN, Giorgio. Estancias. La palabra y el fantasma en la cultura occidental. Valencia: Pre-Textos, 1995.

Medios sin fin. Valencia: Pre-Textos, 2001.

“La potencia del pensamiento." En La potencia del pensamiento. Ensayos y conferencias, 351368. Buenos Aires, Adriana Hidalgo editora, 2007.

Signatura rerum. Sobre el método. Buenos Aires: Adriana Hidalgo editora, 2009.

AMADO, Ana. “Cine, historia, memoria: Notas sobre Histoire(s) du cinema, de J.-L. Godard”. Salon Kritik, abril 2009.

BUCHLOH, Benjamin. "Procedimientos alegóricos: apropiación y montaje en el arte contemporáneo". En: Formalismo e historicidad: modelos y métodos en el arte del siglo XX. Madrid: Akal, 2004.

DE LA DURANTAYE, Leland. Giorgio Agamben. A Critical Introduction. Stanford: Stanford University Press, 2009.

DIDI-HUBERMAN, Georges. Aby Waburgr et l'archive des intensités. En: Études photographiques 10 , 2001, pp. 144-160.

L'image survivante. Histoire de l'art et temps des fantômes selon Aby Warburg, Paris: Les éditions de Minuit, 2002. 
Ante el tiempo. Historia del arte y anacronismo de las imágenes. Buenos Aires: Adriana Hidalgo editora, 2007.

La ressemblance par contact. Anchéologie, anachronisme et modernité de l'empreinte. París: Les éditions de Minuit, 2008.

Passés Cités par JLG. L'œil de l’histoire, 5. París : Les Éditions de Minuit, 2015.

EISENSTEIN, Sergei. Film Form: Essays in Film Theory, New York: Harcourt, 1949.

FOUCAULT, Michel. L'Archéologie du savoir. París: Gallimard, 1969.

GUASCH, Anna Maria. Autobiografías visuales: del archive al índice. Madrid: Siruela, 2009.

Arte y archivo, 1920-2010. Genealogías, tipologías y discontinuidades. Madrid: Akal, 2011.

HAGELSTEIN, MAUD. «Mnemosyne et le Denkraum renaissant. Pratique du document visuel chez Aby Warburg». En: MethIS [online], Volume 2 - 2009. Pratiques du document, 87-111. URL: http://popups.ulg.ac.be/2030-1456/index.php?id=271.

HIRSCH, Marianne. The Generation of Postmemory. Writing and Visual Culture After the Holocaust, Nueva York: Columbia University Press, 2012.

MICHAUD, Philippe-Alain. «Zwischenreich. Mnemosyne, ou l'expresitivé sans sujet ». En Sketches. Histoire de l'art, cinéma. París: Kargo \& L'Éclat, 2006.

NIETZSCHE, Friedrich. Sobre la utilidad y el perjuicio de la historia para la vida. Madrid: Editorial Biblioteca Nueva, 1999.

O’SUlLIVAN, Simon. “The Aesthetics of Affect. Thinking Art Beyond Representation”. En: Angelaki. Journal of the Theoretical Humanities, vol. 6, $\mathrm{n}^{\circ}$. 3, 2001, pp. 25-35.

OSTHOFF, Simone. Performing the Archive: The Transformation of the Archives in Contemporary Art from Repository of Documents to Art Medium. Nueva York: Atropos Press, 2009.

SÁNCHEZ-BIOSCA, Vicente. "Un archive insomne: producción y migración de imágenes cinematográficas del ghetto de Varsovia." História: Questões \& Debates, Curitiba 61, Editora UFPR, 2014, pp. 79-103.

SIEREK, Karl. Images oiseaux. Aby Warburg et la théorie des médias. París: Klincksieck, 2009.

Recebido em 14/03/2016. Aprovado em 23/06/2016.

Title: Dematerialization of history in the era of the (cinematographic) archive. From Aby Warburg to Jean-Luc Godard

Abstract: Aby Warburg's Mnemosyne proposes a writing of art history that escaped from chrono-normativities of historiography that crystallized before their eyes. In his atlas, he sought an anachronistic point of view where past and present transform each other to configure what Walter Benjamin could call "constellation”. Both Warburgian experience and some cinematographic archives of Jean-Luc Godard pose epistemological problems very contemporary: how configure an archive about the past and how to restore to (visual) documents a place in the historical process? This article explores how the Warburg's method illuminates contemporary productions on the relationship between film and history and how it continues functioning as a matrix to think the dematerialization of the historical discipline.

Keywords: Aby Warburg. Jean-Luc Godard. Archive. Dematerialization of history.

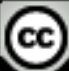

Este texto está licenciado com uma Licença Creative Commons Atribuição 4.0 Internacional. 